\title{
COMPARATIVE STUDY OF INTRAVENOUS IRON SUCROSE AND ORAL IRON IN IRON DEFICIENCY ANAEMIA AMONG PREGNANT WOMEN IN RURAL
}

Meenal. C, Hiremath. P. B, Nidhi Bansal,Thirunaaukarasu, Srikanth. S, Nirmala, Bharathy.

1. Professor \& Head, Department of Obstetrics \& Gynaecology, SVMCH \& RC, Ariyur, Puducherry.

2. Assistant Professor, Department of Obstetrics \& Gynaecology, SVMCH \& RC, Ariyur, Puducherry.

3. Assistant Professor, Department of Community Medicine, SVMCH \& RC, Ariyur, Puducherry.

4. Associate Professor, Department of Community Medicine, SVMCH \& RC, Ariyur, Puducherry.

5. Associate Professor, Department of Physiology, SVMCH \& RC, Ariyur, Puducherry.

6. House Surgeon, SVMCH \& RC, Ariyur, Puducherry

\section{CORRESPONDING AUTHOR}

Dr. Hiremath P.B.

Dept of OBGY,

SVMCH \& RC, Ariyur,

Puducherry-605102

E-mail: drhiremath2@yahoo.co.in

Ph: 00917639672385

ABSTRACT: Iron deficiency anaemia (IDA) is the commonest medical disorder in pregnancy in developing countries including India. It is not only the leading cause of maternal death but also an aggravating factor in haemorrhage, sepsis and toxemia. Conditions such as abortions, premature births, antepartum haemorrhage, post partum haemorrhage and low birth weight were especially associated with low haemoglobin levels in pregnancy. $40-80 \%$ of women belonging to low socio economic groups are anaemic in the last trimester of pregnancy. Research on alternative to Iron Folic acid (IFA) supplementation is being carried out in some parts of India. Intravenous (IV) Iron sucrose therapy is one such alternative. This study was planned to evaluate the response to intravenous iron sucrose in anaemic pregnant women from rural areas and compare it with oral iron therapy.

KEY WORDS: Anaemia, Pregnancy, Iron sucrose, Injectable iron, Oral iron

INTRODUCTION: Nutritional iron deficiency is the most common deficiency disorder in the world, affecting more than two billion people worldwide, with pregnant women at particular risk ${ }^{1,2}$. It is not only the leading cause of maternal death but also an aggravating factor in haemorrhage, sepsis and toxemia. Conditions such as abortions, premature births, ante partum haemorrhage, post partum haemorrhage and low birth weight were especially associated with low haemoglobin levels in pregnancy. In the newborn IDA is associated with poor performance in the Bayley mental development index ${ }^{3}$. In India, $40-80 \%$ of women belonging to low socio economic groups are anaemic in the last trimester of pregnancy. The majority of patients with severe anaemia are detected in the third trimester, the reason being that the demand of iron is more during that period 4,5 .

The causes of increased prevalence of anaemia in tropics are faulty dietary habits, faulty absorption, intestinal worm infestation, increased iron loss due to sweat (15mg/month) and increased demand during pregnancy ${ }^{6}$.

Research on alternative to Iron Folic acid (IFA) supplementation is being carried out in some parts of India. Intravenous (IV) Iron sucrose therapy is one such alternative. It is a brown 
sterile aqueous complex of polymer iron hydroxide in sucrose. Following I.V sucrose, maximum level of iron is seen in plasma after 10 minutes. It is dissociated in reticulo-endothelial system into iron and sucrose. The iron injection is rapidly cleared from plasma in $6 \mathrm{hrs}$. Among healthy volunteers, after intravenous administration of iron sucrose, a competitive exchange of iron to transferrin was observed due to the lower stability of iron sucrose. There is increasing evidence to show that IV iron sucrose results in rapid resolution of IDA. Iron sucrose therapy is being tried among anaemic pregnant women in developed world7. Intravenous iron sucrose therapy at a low dose has been accepted to practice in developed countries. However, limited studies have been reported on IV iron sucrose for anaemic pregnant women from India. Hence, this study was planned to evaluate the response to intravenous iron sucrose in anaemic pregnant women from rural areas and compare it with oral iron therapy.

OBJECTIVES: To compare the effect of Intravenous Iron Sucrose with Oral Iron tablet in anaemic pregnant women in a tertiary hospital.

INCLUSION CRITERIA: Anaemic ( $\mathrm{Hb} 5-10 \mathrm{gms} \%$ ) pregnant women in IInd and IIIrd trimesters with no other risk factors

\section{EXCLUSION CRITERIA:}

1. Anaemic pregnant women with gestational diabetes, hypertension, heart disease, epilepsy

2. Anaemic pregnant women with $\mathrm{Hb}<4.9 \mathrm{gm}$ in II and III Trimester

3. Anaemic pregnant women with known allergy to parenteral Iron

4. Pregnant women who had received blood transfusion during this pregnancy

MATERIALS AND METHODS : This Randomized Clinical Trial was conducted in the antenatal clinic in Sri Venkateshwara Medical College Hospital \& Research Centre (SVMCH\&RC), Ariyur Puducherry over a period of 12 months in a sample size of 484. All anaemic (Hb 5- 10gms \%) pregnant women in II and III trimesters with no other risk factors were included and those with gestational diabetes, hypertension, heart disease or epilepsy were excluded. Anaemic pregnant women with very severe anaemia or those who had received blood transfusion during this pregnancy were also excluded from the study. All the pregnant women were screened for anaemia. Haemoglobin estimation was done by Cyanmethaemoglobin (HICN) method. Peripheral Smear was done to type the anaemia. Severity of anaemia was judged according to ICMR criteria.

All eligible patients were randomly allocated either to the study group (IV iron sucrose) or the control group (Oral Iron) and written consent was taken. Deworming with 400mg of Albendazole was done for all the participants. For the study group, the women were admitted in day care unit and $200 \mathrm{mg}$ Iron sucrose dissolved in $100 \mathrm{ml}$ normal saline was given intravenously for a period of 30 mins in two sittings 24 hours apart. Adverse reactions were monitored. Haemoglobin estimation was done after 4 weeks. All the women in this group were given uniform dosage of iron sucrose. We did not calculate the optimal dose of iron sucrose required for each woman. This is to study the response to a uniform dose of iron sucrose over a range of pre treatment $\mathrm{Hb}$ value. For the control group, Iron tablets containing 200mg Ferrous Sulphate were given for 4 weeks followed by Haemoglobin estimation. Descriptive and Inferential Statistical analysis was done using SPSS 17. Ethical Committee Clearance was obtained and the trial was registered in The Clinical Trial Registry of India. 
Demographic characteristics of women in the study or control group were not compared. We have not attempted to standardize the diet, parity, spacing between subsequent pregnancies or any other factors affecting the development of anaemia and iron stores.

\section{RESULTS:}

\section{I) Prevalence and severity of IDA in pregnancy}

In the 484 women included in our study, the largest proportion of anaemic women (310 or $62.44 \%$ ) fell into the category of moderate anaemia, while severe anaemia was found in 174 (35.96\%) women. Table 1

\section{II) Response to oral iron supplements}

Out of the 247 women , 32 women could not be reassessed at 4 weeks for a variety of reasons(abortions ,failure to take tablets due to gastric irritation \& constipation, lost to follow up).The data presented is therefore based on the remaining 215 who attended for the second $\mathrm{Hb}$ estimation at 4 weeks following therapy. Table 2 shows the pre and post treatment $\mathrm{Hb}$ levels. 208(96.74\%) showed a rise in $\mathrm{Hb}$, the majority $(77.4 \%)$ by upto a maximum of $0.6-0.9 \mathrm{gm} / \mathrm{dl}$. The remaining 7 (3.26\%) patients showed either no rise or even a fall in $\mathrm{Hb} 208$ patients who responded showed a mean rise $0.84 \mathrm{gm} / \mathrm{dl}$ (s.d 0.21). Table 2a, 2b, 2c.

\section{III) Response to I.V Iron sucrose}

Follow up $\mathrm{Hb}$ estimations were obtained at 4 weeks in 195 women (42 did not attend for follow up $\mathrm{Hb}$ estimation). A rise between $2-2.9 \mathrm{gm} / \mathrm{dl}$ was seen in $71.64 \%$ of women and a rise more than $3 \mathrm{gm} / \mathrm{dl}$ was seen in $24.22 \%$ of these women.194 (99.48\%) of the 195 responded and had a mean rise in $\mathrm{Hb}$ of $2.77 \mathrm{gm} / \mathrm{dl}$ (s.d 0.35). Table 3a, 3b, 3c.

\section{IV) Oral Iron versus I.V Iron sucrose}

The majority of women showing a rise in $\mathrm{Hb}$ in response to oral supplementation had a maximum rise of up to $0.6-0.9 \mathrm{gm} / \mathrm{dl}$ over 10 weeks, while I.V Iron sucrose resulted in a majority of women who responded raising their $\mathrm{Hb}$ by $2-2.9 \mathrm{gm} / \mathrm{dl}$ over 4 weeks $(\mathrm{p}<0.001$ significant). In Oral Iron group, no woman had a rise of $\mathrm{Hb}$ by more than 2gm/dl while 186 $(95.38 \%)$ in the I.V Iron sucrose group did so. Figure 1

\section{V) Adverse reactions to I.V Iron sucrose and Oral Iron :}

Minor adverse reactions, which included burning at the infusion site, itching, giddiness and G.I symptoms like nausea and vomiting occurred, but there were no major adverse reactions.

For the oral iron group, minor adverse reactions like nausea, vomiting, constipation were noted in a few cases. However, there were no major adverse reactions.

DISCUSSION: Iron deficiency anaemia continues to be a major health problem in India and other developing countries. The same is corroborated by all the recent prevalence studies-10. The National Nutritional Anaemia Control Programme in various Indian states has failed to achieve the targeted goals ${ }^{11}$.

In our study, we followed the practice of universally deworming all women prior to commencing the iron supplements whether oral or intravenous. The Hb rise in both the arms of the study was optimal, although the difference in $\mathrm{Hb}$ rise in both groups was significantly in favour of the Intravenous Iron Sucrose group.

Comparative studies between oral \& IV Iron sucrose have shown a mean higher birth weight of $250 \mathrm{gm}$ was noted in IV group ${ }^{12,13}$. It is impossible in routine clinical practice to ensure 
compliance for oral iron tablets on a day to day basis, whereas intravenous iron therapy surmounts this problem of compliance completely. Also, as compared to other parenteral routes, iron sucrose is free of significant allergic reactions and so can be used widely at all centres and subcentres with safety.

Our study shows that 2 doses of $200 \mathrm{mg}$ each of Iron sucrose given intravenously significantly increases the $\mathrm{Hb}$ levels in a short period of 4 weeks with no major adverse reactions. This improvement over a short period, makes the intravenous iron sucrose administration suitable for correction of anaemia even in advanced pregnancies. Morbidity associated with blood transfusion and it's cost considerations further emphasize the importance of including I.V Iron sucrose administration into routine clinical practice.

Initially there were certain problems associated with parenteral Iron administration. Studies conducted to assess \& compare efficacy \& safety of IV Iron sucrose with daily oral ferrous Sulphate showed that Intravenous Iron sucrose corrects iron-deficiency anaemia during pregnancy more quickly than oral iron ${ }^{14}$. The challenge was to deliver infusions at the rural level and that too in repeated settings. However, it is feasible to administer a single dose of iron sucrose as a intravenous push over 10 minutes which neither requires hospital administration nor the complex set up for I.V infusion, also reducing the cost implications.

Still the availability of the drug at low cost to the rural population is a constraint. We would hereby take the humble opportunity to request that a free of cost supply of the same could be made available from the Government of India. This will go a long way in reducing the expenditure incurred by the health care system, thereby decreasing the maternal morbidity and mortality and improving the perinatal outcome that a single universal dose of iron sucrose given intravenously, could go a long way in preventing iron deficiency anaemia in pregnancy.

CONCLUSION: Intravenous Iron sucrose administration can correct anaemia in a short period even in advanced pregnancy and prevent associated maternal and perinatal complications.

\section{REFERENCES:}

1. K. Kalaivani. Prevalence \& consequences of anaemia in pregnancy. Indian J Med Res 130:November 2009(627-633).

2. Ezzati M, Lopus AD, Dogers A, Vander HS, Murray C.Selected major risk factors and global and regional burden of disease. Lancet 2002; $360: 1347-60$.

3. Oski, FA Iron deficiency - facts and fallacies. Paediatr Clin North America, 1985; 32: 493-497.

4. Sharma A, Patnaik R, Garg S, Ramachandran P. Detection \& management of anaemia in pregnancy in an urban primary health care institution. Indian J Med Res 2008; 128 :4551.

5. Prema Ramachandran. Anaemia in pregnancy. In: Ratnam SS, Bhasker Rao K, Arulkumaran S, editors.Obstetrics and gynaecology for postgraduates, Vol 1. Madras:orient Longman; 1992. p. 42-53.

6. Government of India. National Family Health Survey-3(2005-2006).Vol I Chapter-8, Maternal Health .International Institute for Population Sciences 2007: 191-222.

7. Textbook of Obstetrics - D.C.Dutta, Sixth edition 2004.chapter 19;Anaemia in Pregnancy (262-277). 
8. Williams Obstetrics, 22nd edition. Chapter-51, Hematological Disorders; Iron Deficiency Anaemia 2005 (1145-1146).

9. Agarwal K N, Agarwal D.K,Sharma Actal-Prevalence of anaemia in pregnant women in pregnant and lactating women in INDIA. Indian J Med Res 2006:124:173;184.

10. Toteja G, Singh P, Micronutrient deficiency disorders in 16 districts of India. Reports of an ICMR task force study -District Nutrition Project Part I. 2001.

11. Government of India. National Family Health Survey-3(2005-06), Vol-I,Chapter -8. Maternal Health .International Institute for Population Sciences 2007:191-222.

12. Vijayaraghavan K, Brahman GNV, Nair KM, Akbar D, Pralhad Rao N. Evaluation of National Nutritional Anaemia Prophylaxis Programme. Indian J Pediatr. 1990;57:183190

13. Al RA, Unlubilgin E, Kandemir O, Yalvac S, Cakir L, Haberal A. Intravenous versus oral iron for treatment of anemia in pregnancy: a randomized trial.Obstet Gynecol. 2005 Dec; 106(6):1335-40.

14. Francoise Bayoumer MD, Carole Subrian-Buisset,Nour Eddine Baka,Henryse Legagneur, Patricia Monnier-Barbarino, Mario claire Laxenaire.Americal journal of obs \& gyn,vol 186, Issue 3, March 2002 ; pg 518-522. Iron therapy in iron def. Anaemia in pregnancy; IV route versus oral route.

\section{TABLE 1: SEVERITY OF ANAEMIA}

Anaemia was categorized according to the criteria established by ICMR. The majority of anaemic women had a moderate degree of anaemia (310 or $64.04 \%$ ) while 174 or $35.96 \%$ of women in our study had severe degree of anaemia.

\begin{tabular}{|l|c|c|}
\hline ANAEMIA(Hb in gm/dl) & \multicolumn{2}{|c|}{ N=484 } \\
\hline & (n) & $(\%)$ \\
\hline Mild(10-10.9) & 0 & - \\
\hline Moderate (7-9.9) & 310 & 64.04 \\
\hline Severe (4-6.9) & 174 & 35.96 \\
\hline Very severe (<4) & 0 & - \\
\hline TOTAL & 484 & 100 \\
\hline
\end{tabular}

TABLE 2 : RESPONSE TO ORAL IRON SUPPLEMENTS: Oral iron was administered at $200 \mathrm{mg}$ twice daily for 4 weeks, $\mathrm{Hb}$ estimation was performed before and after the 4 weeks course of therapy. Women with unchanged $\mathrm{Hb}$ or those whose $\mathrm{Hb}$ fell compared to pre-treatment values, were considered Non Responders. 208(96.74\%) women responded to iron supplementation by showing a rise in $\mathrm{Hb}$, the majority (77.45\%) showing a rise of upto 0.6-0.9 gm/dl. 
TABLE 2A :

\begin{tabular}{|l|c|c|}
\hline RESPONSE & FREQUENCY & PERCENTAGE \\
\hline Responders & 208 & 96.74 \\
\hline Non responders & 7 & 3.26 \\
\hline Total & 215 & 100 \\
\hline
\end{tabular}

TABLE 2B:

\begin{tabular}{|l|c|c|}
\hline NON RESPONDERS & FREQUENCY & PERCENTAGE \\
\hline Decreased & 6 & 85.71 \\
\hline Same & 1 & 14.29 \\
\hline Total & 7 & 100 \\
\hline
\end{tabular}

TABLE 2C :

\begin{tabular}{|l|c|c|}
\hline $\begin{array}{l}\text { RESPONDERS } \\
\text { (Hb rise) }\end{array}$ & FREQUENCY & PERCENTAGE \\
\hline UPTO 0.5gm/dl & 12 & 5.77 \\
\hline $0.6-0.9$ & 161 & 77.4 \\
\hline $1.0-1.9$ & 35 & 16.83 \\
\hline $2-2.9$ & 0 & - \\
\hline$>3$ & 0 & - \\
\hline Total & 208 & 100 \\
\hline
\end{tabular}

\section{TABLE 3: RESPONSE TO IV IRON SUCROSE}

2 doses of I.V Iron sucrose $200 \mathrm{mg}$ each were administered daily for 2 days. Hb was assessed prior to treatment, and again at 4 weeks after therapy. In the 195 women available for follow up 195 women(99.48\%) registered a rise in $\mathrm{Hb}$ across all ranges of anaemia. 95.86\% had a rise of more than $2 \mathrm{gm} / \mathrm{dl}$ within 4 weeks. 42 women were lost to follow up.

TABLE 3A:

\begin{tabular}{|l|c|c|}
\hline RESPONSE & FREQUENCY & PERCENTAGE \\
\hline Responders & 194 & 99.48 \\
\hline Non responders & 1 & 0.52 \\
\hline Total & 195 & 100 \\
\hline
\end{tabular}

TABLE 3B:

\begin{tabular}{|l|l|l|}
\hline NON RESPONDERS & FREQUENCY & PERCENTAGE \\
\hline Decreased & 0 & - \\
\hline Same & 1 & 100 \\
\hline Total & 1 & 100 \\
\hline
\end{tabular}


TABLE 3C:

\begin{tabular}{|l|c|c|}
\hline $\begin{array}{l}\text { RESPONDERS } \\
\text { (Hb rise) }\end{array}$ & FREQUENCY & PERCENTAGE \\
\hline UPT0 0.5gm/dl & 0 & - \\
\hline $0.6-0.9$ & 0 & - \\
\hline $1.0-1.9$ & 8 & 4.14 \\
\hline $2-2.9$ & 139 & 71.64 \\
\hline$>3$ & 47 & 24.22 \\
\hline Total & 194 & 100 \\
\hline
\end{tabular}

\section{FIGURE 1: RESPONSE TO ORAL IRON VERSUS IV IRON SUCROSE}

Among the women receiving oral iron the majority 161(77.4\%) showed an increase of $\mathrm{Hb}$ of 0.6-0.9 gm\%, while in the I.V Iron sucrose group the majority $139(71.64 \%)$ showed a greater rise of 2-2.9 gm\%. No patients in the oral Iron group showed an increase in Hb of over $2 \mathrm{gm} / \mathrm{dl}$, while a majority of 186 (95.86\%) in the I.V Iron sucrose group showed a similar increase.

Figure 1: Response to Iron therapy

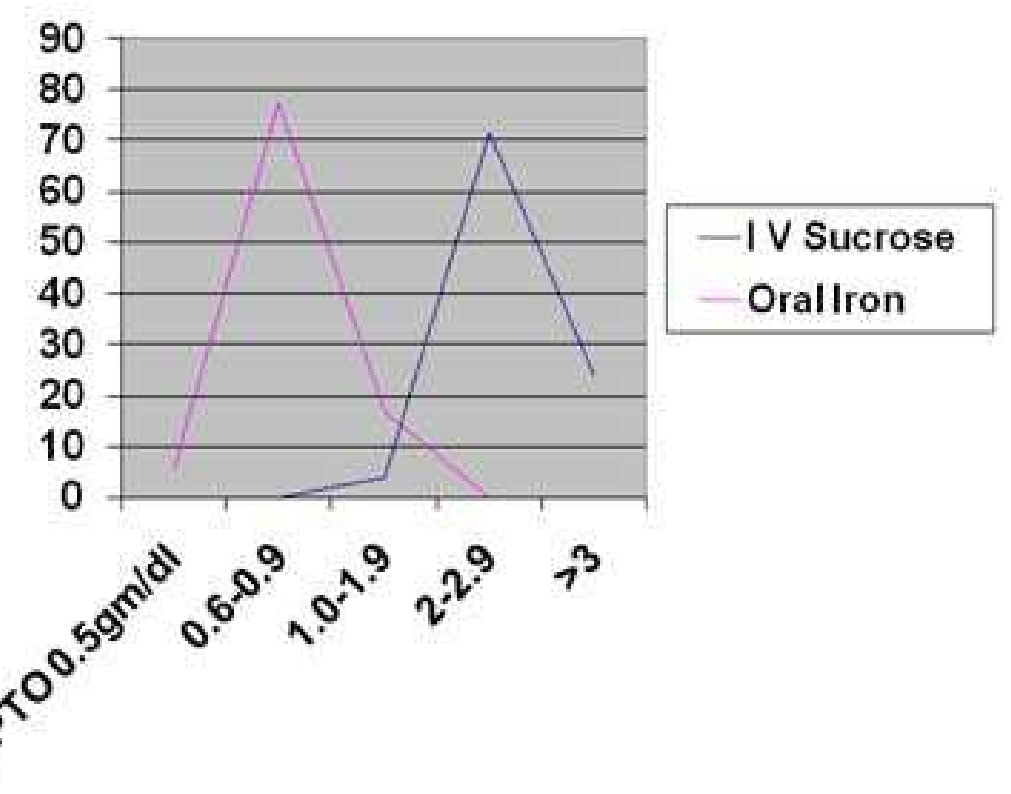

